\title{
Association Analysis of Genetic Polymorphisms in the CDC2 Gene with Late-Onset Alzheimer Disease
}

\author{
Xueying Liang ${ }^{a} \quad$ Nathalie Schnetz-Boutaud ${ }^{\mathrm{a}}$ Jackie Bartlett ${ }^{\mathrm{a}}$ \\ Brent M. Anderson ${ }^{a}$ Harry Gwirtsman ${ }^{b}$ Don Schmechel ${ }^{c}$ Regina Carney ${ }^{d}$ \\ John R. Gilbert ${ }^{d}$ Margaret A. Pericak-Vance ${ }^{d}$ Jonathan L. Haines ${ }^{a}$ \\ ${ }^{a}$ Center for Human Genetics Research and Department of Molecular Physiology and Biophysics, \\ Vanderbilt University, and ${ }^{b}$ Department of Psychiatry, VA Hospital Medical Center, Nashville, Tenn., and \\ cDepartment of Neurology and d Center for Human Genetics and Department of Medicine, Duke University, \\ Durham, N.C., USA
}

\section{Key Words}

Alzheimer disease - CDC2 - Cell division cycle $2 \cdot$ Genetics, complex disorders $\cdot$ Single nucleotide polymorphisms

\begin{abstract}
Background: Alzheimer disease (AD) is a complex neurodegenerative disorder resulting from multiple genetic and non-genetic factors. Linkage studies indicated that chromosome 10 has at least one locus for this disease. The cell division cycle 2 (CDC2) gene, which is close to one of the linkage regions, has previously been associated with the risk of $A D$ with an odds ratio of 1.78 . Biologically, CDC2, which is involved in paired helical filament-tau formation, is thought as a candidate gene in AD. Methods: In this study, six single nucleotide polymorphisms spanning the entire gene were selected and examined for association for late-onset $A D$ (LOAD) in two large independent datasets. A family-based dataset including 1,337 Caucasian discordant sib pairs and an independent dataset of 745 Caucasian cases and 998 controls for LOAD were used. Family-based association tests and logistic regression conditional on the apolipoprotein $\mathrm{E}$ genotype and sex were applied to association study in familybased and case-control datasets, respectively. Results: Neither dataset demonstrated any association with LOAD in our
\end{abstract}

samples with all $p$ values $>0.16$. Conclusion: Our results suggest that if any contribution of common genetic variants in $\mathrm{CDC} 2$ to the risk of developing $\mathrm{AD}$ exists, it is likely to be very small.

Copyright $\odot 2007$ S. Karger AG, Basel

\section{Introduction}

Alzheimer disease (AD) is the most common form of dementia among the elderly. This progressive neurodegenerative disorder accounts for more than half of all cases of dementia among people over 65 years of age [1]. Clinically, $\mathrm{AD}$ is slowly progressive, resulting in memory loss and alterations in higher intellectual function and cognitive abilities [2]. Pathologically, AD is characterized by neurofibrillary tangles in the neurons of the cerebral cortex and hippocampus and the deposition of amyloid within senile plaques and cerebral blood vessels [3].

$\mathrm{AD}$ is a complex neurodegenerative disorder resulting from multiple genetic and non-genetic factors [4]. The only well-established genetic susceptibility factor for non-mendelian late-onset $\mathrm{AD}$ (LOAD) is the $\varepsilon 4$ allele of the apolipoprotein $\mathrm{E}(A P O E)$ gene [5]. However, the presence of the APOE-4 allele is neither necessary nor suffi- 
Table 1. Study populations for AD including family-based and case-control samples

\begin{tabular}{lrrrr}
\hline Family & Overall & NIMH & NCRAD & CAP \\
\hline $\begin{array}{l}\text { Family-based dataset } \\
\text { Total family }\end{array}$ & & & & \\
$\quad$ Total pedigrees & 730 & 352 & 154 & 224 \\
$\quad$ Affected individuals & 1,521 & 807 & 315 & 390 \\
$\quad$ Unaffected individuals & 974 & 331 & 162 & 481 \\
$\quad$ DSPs & 1,337 & 629 & 269 & 439 \\
$\quad$ Independent DSPs & 674 & 283 & 129 & 262 \\
$\quad$ Pedigrees with at least one DSP & 406 & 165 & 75 & 166 \\
$\quad$ ARPs & 64 & 66 & 26 & 96 \\
$\quad$ Pedigrees with at least one ARP & 567 & 352 & 122 & 22 \\
Multiplex family & 922 & 517 & 190 & 225 \\
$\quad$ Total pedigrees & 707 & 418 & 150 & 139 \\
$\quad$ ASPs & 534 & 331 & 118 & 85 \\
$\quad$ Independent ASPs & & & & \\
$\quad$ Pedigrees with at least one ASP & 745 & 1 & 42 & 702 \\
\hline Case-control dataset & 998 & 0 & 0 & 998 \\
Cases & & & & \\
Controls & & & & \\
\hline
\end{tabular}

$\mathrm{ARP}=$ Affected relative pairs; $\mathrm{ASP}=$ affected sib pairs; CAP = Collaborative Alzheimer Project; DSP = discordant sib pairs; NCRAD = National Cell Repository for Alzheimer's Disease; NIMH = National Institute of Mental Health repository. cient to cause $\mathrm{AD}$, indicating that additional genetic or non-genetic factors influencing the $\mathrm{AD}$ risk are yet to be identified. To discover additional susceptibility genes, genome scans were initiated resulting in the identification of genomic regions of interest, predominantly on chromosomes 2, 9, 10, 12 and 15 [6-9]. In 2000, three quite different approaches led to convincing evidence that there is at least one other susceptibility gene for $\mathrm{AD}$ on chromosome 10q. Two linkage studies gave strong evidence of a locus at almost exactly the same location (D10S1225): one using plasma levels of the amyloid $\beta$ brain-deposited fragment of the amyloid precursor protein as a continuous phenotype, and the other using a categorical disease phenotype. A third candidate gene linkage and association analysis approach interestingly found a maximum signal $\sim 35-60 \mathrm{cM}$ distal to the previous studies (D10S583) [10-12]. Some of the over 240 genes in the broad region spanned by these results may be considered as positional candidates because they are also hypothesized to interfere with $\mathrm{AD}$-related biochemical pathways. The cell division cycle 2 (CDC2) gene is located within this linkage peak $(2 \mathrm{Mb}$ from the marker D10S1225) and is thought to be one of the main candidate kinases involved in the abnormal phosphorylation of tau, which is involved in neurofibrillary tangles, a hallmark of $\mathrm{AD}$. $\mathrm{CDC} 2$ is also designated as $\mathrm{CDK} 1$ or $\mathrm{p} 34^{\mathrm{CDC} 2}$, and its neuron-specific form is CDK5. CDC2 is involved in the critical event at the point of convergence of mitosis and neurodegeneration pathways in AD. Therefore, $\mathrm{CDC} 2$ is a reasonable positional and functional candidate for an association with AD. Johansson et al. [13] reported that a variation in the $\mathrm{CDC} 2$ gene is associated with $\mathrm{AD}$ at an odds ratio (OR) of 1.78 (95\% confidence interval, CI: 1.18-2.68) in a dataset of 272 Caucasian AD cases and 160 controls.

To test whether allelic variation in this potential important candidate gene confers susceptibility to $\mathrm{AD}$, we genotyped six single nucleotide polymorphisms (SNPs) across CDC2 in two independent samples: family-based and case-control samples. Our data suggest the lack of an association of the variations in the CDC2 gene with $\mathrm{AD}$.

\section{Materials and Methods}

\section{Study Populations}

Family Sample

We used a total of 1,337 affected discordant sib pairs defined by 1,521 LOAD patients (minimum age at onset, AAO $\geq 60$ years) and 974 unaffected individuals in these families (table 1). Spouses of $\mathrm{AD}$ patients were used as controls in the case-control dataset if individuals had no obvious signs of cognitive or neurological 


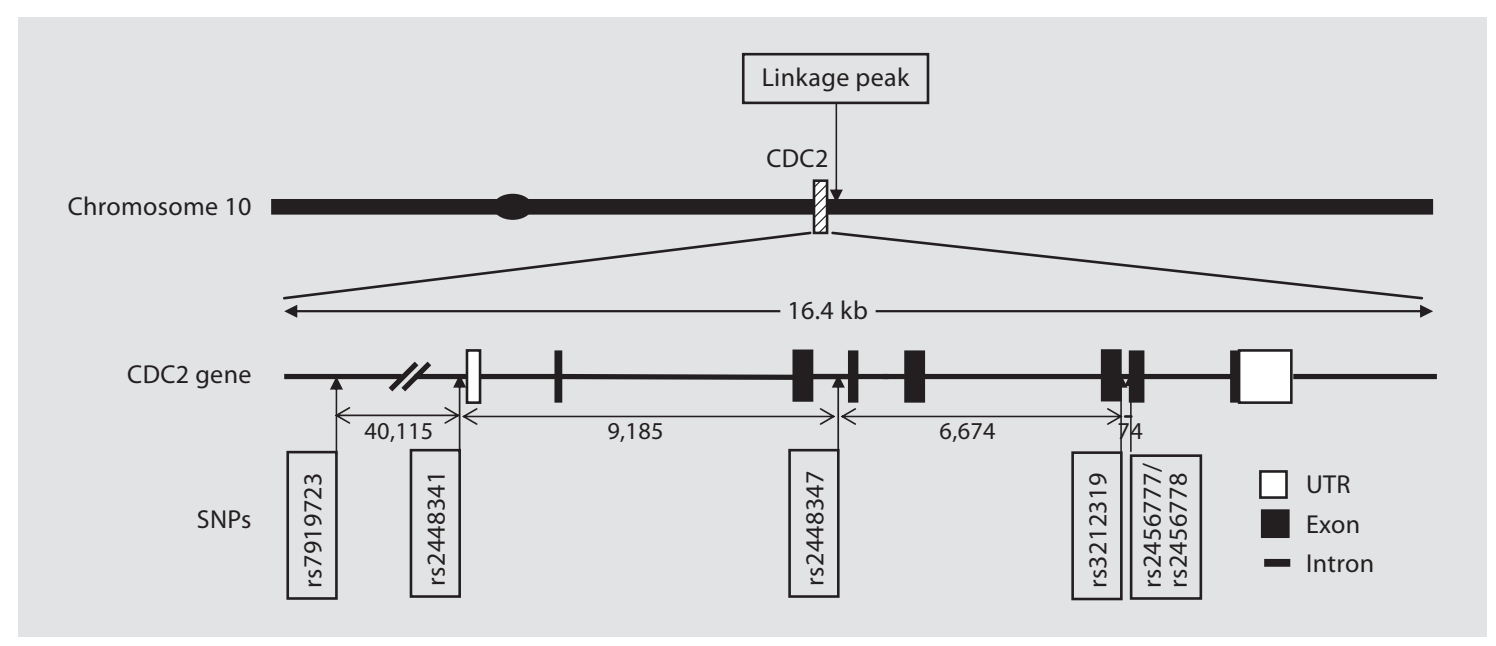

Fig. 1. Gene structure and relevant features of CDC2 and surrounding sequences. The relevant SNPs are labeled with the dbSNP rs number. The distances between SNPs are shown in base pairs.

impairment when enrolled in the study as determined by personal interview by clinical personnel. Family data were ascertained by the following centers: the National Cell Repository for Alzheimer's Disease at Indiana University; the Collaborative Alzheimer Project, including Duke and Vanderbilt Universities and University of California at Los Angeles, and the National Institute of Mental Health repository. All participants were Caucasian Americans. Written consent was obtained from all participants in agreement with protocols approved by the institutional review board at each contributing center. $\mathrm{AD}$ was diagnosed according to the NINCDS-ADRDA criteria [14]. AAO was recorded as that age at which the first symptoms were noted by the participant or a family member. Mean AAO \pm SD was $72.9 \pm 6.4$ years in affected individuals in the family-based sample. The mean age at examination (AAE) \pm SD was $80.1 \pm 7.1$ and $69.9 \pm$ 11.2 in affected and unaffected individuals, respectively. In the $\mathrm{AD}$-affected group, $67.3 \%$ were female, and in the unaffected group $56.2 \%$ were female.

\section{Case-Control Sample}

Our case-control sample consists of 745 unrelated cases with probable or definite AD and 998 unrelated cognitively normal elderly controls who were either the spouses of $\mathrm{AD}$ patients or subjects recruited from the outpatient clinics of the participating institutions. Cases and controls were collected through the Center for Human Genetics Research (CHGR) at Vanderbilt University and the Center for Human Genetics (CHG) at Duke University. Criteria for AD diagnosis and screening of unaffected relatives were the same as described above. Controls had no obvious signs of cognitive or neurological impairment when enrolled in the study as determined by personal interview by clinical personnel of the CHGR at Vanderbilt University and CHG at Duke University. All individuals included in this study are Caucasian. The control group's mean AAE \pm SD was $72.0 \pm 6.3$ years, while the case group's mean AAE \pm SD was $76.5 \pm 6.53$ years. Of the AD cases, $63.3 \%$ were female, while $58.5 \%$ of the controls were female.

\section{SNP and Genotyping}

Following informed consent, blood samples were collected from each individual. Genomic DNA was obtained from the $\mathrm{Na}$ tional Institute of Mental Health Repository and NCRAD, or extracted from whole blood (Collaborative Alzheimer Project) using the Puregene system (Gentra Systems, Minneapolis, Minn., USA). All samples were coded and stored at $4^{\circ} \mathrm{C}$ until used.

A map of the CDC2 region and SNPs studied is shown in figure 1. The CDC2 gene structure and transcript information were extracted from the Ensembl database (http://www.ensembl.org) according to the NCBI human genome sequence assembly build 35 (http://www.ncbi.nih.gov). Applied Biosystems (http://home. appliedbiosystems.com) web sites were mined to select all available SNPs according to locations relative to other selected SNPs, high minor allele frequency $(\geq 0.25)$, and availability of quality assays during the time when we did the genotyping. SNP genotyping was performed using Assays-On-Demand ${ }^{\mathrm{TM}}$ or Assay-ByDesign $^{\mathrm{TM}}$ with the ABI PRISM ${ }^{\circledR} 7900$ HT Sequence Detection System (Applied Biosystems, Foster City, Calif., USA). Amplification was performed in a 384-well DNA Engine Tetrad ${ }^{\circledR} 2$ Peltier Thermal Cycler (MJ Research, Waltham, Mass., USA) with the following conditions: $94^{\circ} \mathrm{C}-10 \mathrm{~min} ; 92^{\circ} \mathrm{C}-15 \mathrm{~s}, 60^{\circ} \mathrm{C}-1 \mathrm{~min}(50$ cycles); $4^{\circ} \mathrm{C}$-hold.

SNPs rs2456777 and rs2456778 reside right next to each other ([A/G], [A/T]), and a standard Taqman probe cannot detect adjacent SNPs. Thus we defined the most common haplotypes by sequencing 20 Centre d'Etude du Polymorphisme Humain (CEPH) individuals. The two most common haplotypes for these two SNPs are AA and GT, allowing us to develop a single assay to test for the haplotype. Then we designed probes and primers oriented $5^{\prime}$ to $3^{\prime}$. The probes are aagaaatttttAA/GTtttcctgtttt and forward primer is $5^{\prime}$-AAAGGTAACATATATGTAACAATGAGATTACATTTA-3', reverse primer is 5'-TGGGAGTGCCCAAAGCTCTA-3'. We used a Taqman assay to genotype. For those individuals with uncertain haplotype status, sequencing was performed to obtain the genotype. The forward primer is $5^{\prime}$-GAACTAGCAACTAAGAAACCACTTTTCC- $3^{\prime}$ and reverse primer is $5^{\prime}$-CCT- 
TACCGAGAGCAAATCCA-3'. The genotypes were transcribed to be consistent with the Taqman output file. Systematic genotyping errors were minimized by use of a system of quality control checks with duplicated samples [15].

\section{Statistical Methods}

Descriptive Analyses

We tested for linkage disequilibrium (LD) and deviations from Hardy-Weinberg equilibrium using the program Genetic Data Analysis [16]. The LD measures D' and $\mathrm{r}^{2}$ was calculated using the GOLD program [17].

\section{Association Analyses}

Case-control association analyses for single alleles and for genotypes were conducted using logistic regression (SAS Institute, Cary, N.C., USA, version 8.1). We tested three different models. The first is an allele-based model that assumes an additive effect on the log scale for the alleles (e.g. having no A alleles $=0$, having one A allele $=1$, and having two A alleles $=2$ ). The second is an allele-based model which dichotomizes genotype according different alleles (having allele $=0$, and not having allele $=1$ ). The third is a genotype-based model where the most frequent genotype served as a reference genotype and the reference genotype was set to 0 , with the heterozygous genotype set to 1, and the homozygote for the other allele set to 2 . Statistical significance was declared at $\alpha=0.05$.

To adjust for potential confounding due to sex and age, we included sex and AAE as covariates in the regression analysis. In addition, we considered ApoE status using two different models: the 'ApoE 4_2' model which breaks the analysis into two parts, those that have no ApoE 4 allele and those that have at least one ApoE 4 allele, and the 'ApoE_3' model which breaks the analysis into three parts: those that have both ApoE 4 alleles, those that have at least one ApoE 4 allele and those that have no ApoE 4 allele.

$\mathrm{AAO}$ was also analyzed as a dependent variable using a generalized liner model to test the association between AAO and the gene; four models were used. Geno_linear is the model where different genotypes were considered as linear progression; Geno_ group is the model where genotypes were put into groups without linear progression, and Geno_A and Geno_B are the models to group the genotypes into two groups according to two alleles (A and $\mathrm{B}$ ) of the marker (one is the homozygote of one of the two alleles; heterozygote and homozygote of the other allele were in the 2nd group). ApoE status and gender were used as covariates.

Family-based association was conducted using the pedigree disequilibrium test (PDT) for single-locus tests [18] and genotype PDT (GenoPDT) to assess associations between genotypes and the risk of $\mathrm{AD}$ in the family data [19].

\section{Linkage Analysis of the Family Dataset}

Two-point heterogeneity LOD score (logarithm of the odds) analyses were computed using FASTLINK and HOMOG [20]. Because the mode of inheritance for AD is unknown, affected-only parametric analyses were performed using both autosomal dominant and autosomal recessive models with disease allele frequencies of 0.001 and 0.20 , respectively, to model the susceptibility allele. Because it is likely that there is genetic heterogeneity in $\mathrm{AD}$, we applied ordered subset analysis [21] in our linkage analysis to test for a set of families in which the LOD score in a particular region is higher than in the overall dataset. The statistical significance of the increased evidence for linkage relative to evidence for linkage in the entire sample is assessed via random permutation of the order of inclusion of the families to estimate empirical $p$ values. Families were ranked based on APOE LOD score at theta $=0$ (low to high or high to low) and family-specific APOE-4 allele weights (low to high or high to low). Ordered subset analysis was also performed using mean AAO as covariate (low to high or high to low) to test for a subset generating a significantly increased LOD score relative to the overall sample.

Power Calculation

The "PS power and sample size calculation" program [22] was used to calculate the power to detect a CDC2 association given the 745 cases and 998 controls. We used an OR of 1.78, and the probability of exposure in controls of 0.35 as given in the original report of association [13].

\section{Results}

\section{Family-Based Analyses}

CDC2 SNP allele and genotype frequencies for the family-based dataset are listed in table 2. The LD measures ( $\mathrm{D}^{\prime}$ and $\mathrm{r}^{2}$ ) between SNPs are shown in table 3 . There was no significant evidence for deviation from the Hardy-Weinberg equilibrium for all SNPs (table 4). The PDT was conducted in the overall family sample (table 4). None of these tests indicated an association between these six SNPs and AD.

In the linkage analysis, the highest two-point heterogeneity LOD score was generated at SNP rs2448341 (0.11) under the recessive model and allowing heterogeneity. Ordered subset analysis also did not reveal any evidence of linkage in any subset of the data using either ApoE or mean $\mathrm{AAO}$ as the covariate (data not shown).

\section{Case-Control Analyses}

Table 5 shows both allelic and genotypic associations in overall cases and controls. The adjusted ORs are also shown. The highest OR of 1.38 (95\% CI $=0.79-2.43$; $\mathrm{p}=$ $0.26)$ was generated by the rs $2456777 /$ rs 2456778 haplotype when we used the most frequent genotype (GT/GT) as baseline to compare with the haplotypes that do not contain the GT haplotype. AAO, sex and ApoE status were included in the logistic regression as covariates. None of these results is significant. SNP rs2448341 had a marginal effect on AAO when the genotype was the only risk factor in the model $(p=0.01$, table 6$)$, but the effect became non-significant after the models were adjusted by covariates of ApoE status and gender (table 6). 
Table 2. CDC2 SNP allele and genotype frequencies for the family-based dataset

\begin{tabular}{|c|c|c|c|c|c|c|c|}
\hline SNP & $\begin{array}{l}\text { Location } \\
\mathrm{Mb}\end{array}$ & Variation & Allele & $\begin{array}{l}\text { Allele } \\
\text { frequency }\end{array}$ & Genotype & $\begin{array}{l}\text { Affected } \\
\text { (frequency) }\end{array}$ & $\begin{array}{l}\text { Unaffected } \\
\text { (frequency) }\end{array}$ \\
\hline rs7919724 & $62,165,848$ & $\mathrm{~A} / \mathrm{G}$ & $\begin{array}{l}A \\
G\end{array}$ & $\begin{array}{l}0.70 \\
0.30\end{array}$ & $\begin{array}{l}\mathrm{AA} \\
\mathrm{AG} \\
\mathrm{GG}\end{array}$ & $\begin{array}{l}676(0.48) \\
623(0.44) \\
117(0.08)\end{array}$ & $\begin{array}{r}403(0.47) \\
366(0.43) \\
86(0.10)\end{array}$ \\
\hline rs2448341 & $62,205,963$ & $\mathrm{C} / \mathrm{T}$ & $\begin{array}{l}\mathrm{C} \\
\mathrm{T}\end{array}$ & $\begin{array}{l}0.66 \\
0.34\end{array}$ & $\begin{array}{l}\text { CC } \\
\text { CT } \\
\text { TT }\end{array}$ & $\begin{array}{l}632(0.45) \\
628(0.44) \\
157(0.11)\end{array}$ & $\begin{array}{r}373(0.44) \\
383(0.45) \\
99(0.12)\end{array}$ \\
\hline rs2448347 & $62,215,148$ & $\mathrm{~A} / \mathrm{G}$ & $\begin{array}{l}A \\
G\end{array}$ & $\begin{array}{l}0.43 \\
0.57\end{array}$ & $\begin{array}{l}\text { AA } \\
\text { AG } \\
\text { GG }\end{array}$ & $\begin{array}{l}281(0.20) \\
647(0.47) \\
462(0.33)\end{array}$ & $\begin{array}{l}164(0.19) \\
427(0.49) \\
282(0.32)\end{array}$ \\
\hline rs3212319 & $62,221,822$ & $\mathrm{C} /-$ & $\begin{array}{l}\mathrm{C} \\
-\end{array}$ & $\begin{array}{l}0.68 \\
0.32\end{array}$ & $\begin{array}{l}\mathrm{CC} \\
\mathrm{C}- \\
-\end{array}$ & $\begin{array}{l}701(0.47) \\
632(0.43) \\
156(0.10)\end{array}$ & $\begin{array}{l}409(0.45) \\
392(0.44) \\
101(0.11)\end{array}$ \\
\hline $\begin{array}{l}\text { rs2456777 } \\
\text { rs2456778 }\end{array}$ & $\begin{array}{l}62,221,895 \\
62,221,896\end{array}$ & $\begin{array}{l}\mathrm{A} / \mathrm{G} \\
\mathrm{A} / \mathrm{T}\end{array}$ & $\begin{array}{l}\text { AA } \\
\text { GT } \\
\text { AT } \\
\text { GA }\end{array}$ & $\begin{array}{l}0.25 \\
0.74 \\
0.01 \\
0\end{array}$ & $\begin{array}{l}\mathrm{AA} / \mathrm{AA} \\
\mathrm{AA} / \mathrm{GT} \\
\mathrm{AA} / \mathrm{AT} \\
\mathrm{GT} / \mathrm{GT} \\
\mathrm{GT} / \mathrm{AT} \\
\mathrm{AT} / \mathrm{AT}\end{array}$ & $\begin{array}{c}100(0.07) \\
497(0.34) \\
5(0) \\
836(0.58) \\
14(0.01) \\
0(0)\end{array}$ & $\begin{aligned} & 46(0.05) \\
& 299(0.33) \\
& 4(0) \\
& 540(0.60) \\
& 5(0.01) \\
& 0(0)\end{aligned}$ \\
\hline
\end{tabular}

Table 3. LD between SNPs on CDC2 (D' and $\mathrm{r}^{2}$ )

\begin{tabular}{llllll}
\hline & rs7919724 & rs2448341 & rs2448347 & rs3212139 & $\begin{array}{l}\text { rs2456777, } \\
\text { rs2456778 }\end{array}$ \\
\hline rs7919724 & & 0.52 & 0.49 & 0.39 & 0.53 \\
rs2448341 & 0.24 & & 0.61 & 0.54 & 0.65 \\
rs2448347 & 0.14 & 0.30 & & 0.71 & 0.73 \\
rs3212139 & 0.03 & 0.07 & 0.14 & & 0.73 \\
\hline
\end{tabular}

D' is shown in the upper right half (in italics), and $\mathrm{r}^{2}$ is shown in the lower left half. Because $\mathrm{r}^{2}$ is only defined for bi-allelic markers in GOLD, there is no $\mathrm{r}^{2}$ value for the $\mathrm{rs} 2456777 / \mathrm{rs} 2456778$ haplotype.

Table 4. Linkage and association results for the family-based sample

\begin{tabular}{|c|c|c|c|c|c|}
\hline \multirow[t]{2}{*}{ SNP } & \multicolumn{2}{|l|}{ Linkage analysis } & \multirow{2}{*}{$\frac{\text { Association analysis }}{\text { PDT p value }}$} & \multicolumn{2}{|c|}{ HWE (p value) } \\
\hline & $\begin{array}{l}\text { dominant model } \\
\text { HLOD score }\end{array}$ & $\begin{array}{l}\text { recessive model } \\
\text { HLOD score }\end{array}$ & & affected & unaffected \\
\hline rs7919724 & 0.00 & 0.00 & 0.49 & 0.37 & 0.66 \\
\hline rs2448341 & 0.02 & 0.11 & 0.90 & 0.87 & 0.82 \\
\hline rs 2448347 & 0.00 & 0.06 & 0.19 & 0.12 & 0.47 \\
\hline rs3212319 & 0.08 & 0.04 & 0.60 & 0.46 & 0.72 \\
\hline $\begin{array}{l}\text { rs } 2456777 \\
r s 2456778\end{array}$ & 0.00 & 0.00 & 0.42 & 0.18 & 0.20 \\
\hline
\end{tabular}

HLOD = Heterogeneity LOD score; HWE = Hardy-Weinberg equilibrium. 
Table 5. Allelic and genotypic association for case-control samples

\begin{tabular}{|c|c|c|c|c|c|c|c|c|c|c|}
\hline \multirow[t]{2}{*}{ SNP } & \multicolumn{6}{|c|}{ Allelic association } & \multicolumn{4}{|l|}{ Genotypic association } \\
\hline & allele & cases & controls & OR & $95 \%$ CI & $\mathrm{p}$ value & genotype & OR & $95 \%$ CI & $\mathrm{p}$ value \\
\hline \multirow[t]{2}{*}{ rs7919724 } & $\mathrm{A}$ & 693 & 928 & 0.96 & $0.80-1.13$ & 0.60 & GG vs. AA & 1.10 & $0.69-1.73$ & 0.69 \\
\hline & G & 331 & 464 & & & & AG vs. AA & 0.89 & $0.67-1.20$ & 0.45 \\
\hline \multirow[t]{2}{*}{ rs2448341 } & $\mathrm{C}$ & 660 & 897 & 1.00 & $0.85-1.19$ & 0.96 & TT vs. CT & 1.27 & $0.84-1.92$ & 0.27 \\
\hline & $\mathrm{T}$ & 376 & 509 & & & & CC vs. CT & 1.07 & $0.80-1.44$ & 0.65 \\
\hline \multirow[t]{2}{*}{ rs 2448347} & A & 468 & 644 & 1.03 & $0.88-1.21$ & 0.69 & GG vs. AG & 1.25 & $0.91-1.72$ & 0.16 \\
\hline & G & 568 & 756 & & & & AA vs. AG & 1.22 & $0.85-1.73$ & 0.28 \\
\hline \multirow[t]{2}{*}{ rs3212319 } & $\mathrm{C}$ & 767 & 1,076 & 0.92 & $0.77-1.08$ & 0.29 & C- vs. CC & 0.82 & $0.62-1.09$ & 0.18 \\
\hline & - & 502 & 327 & & & & - vs. CC & 0.83 & $0.53-1.31$ & 0.42 \\
\hline rs2456777 & AA & 245 & 305 & - & - & 0.31 & AA/AA, AA/AT, AT/AT vs. GT/GT & 1.38 & $0.79-2.43$ & 0.26 \\
\hline \multirow{2}{*}{ rs2456778 } & GT & 799 & 1,106 & & & & AA/GT, GT/AT vs. GT/GT & 1.10 & $0.81-1.48$ & 0.53 \\
\hline & AT & 4 & 3 & & & & & & & \\
\hline
\end{tabular}

Table 6. Association between AAO and the CDC2 gene in case-control samples

\begin{tabular}{|c|c|c|c|c|c|c|c|c|}
\hline \multirow[t]{2}{*}{ SNP } & \multicolumn{4}{|c|}{ Models: genotype only } & \multicolumn{4}{|c|}{ Models: genotype and covariates (ApoE status and gender) } \\
\hline & Geno_linear & Geno_group & Geno_A & Geno_B & Geno_linear & Geno_group & Geno_A & Geno_B \\
\hline rs7919724 & 0.26 & 0.53 & 0.47 & 0.28 & 0.39 & 0.65 & 0.55 & 0.43 \\
\hline rs2448341 & 0.01 & 0.04 & 0.11 & 0.02 & 0.08 & 0.24 & 0.12 & 0.18 \\
\hline rs2448347 & 0.94 & 0.95 & 0.93 & 0.80 & 0.66 & 0.87 & 0.74 & 0.68 \\
\hline rs3212319 & 0.84 & 0.72 & 0.67 & 0.61 & 0.44 & 0.47 & 0.99 & 0.31 \\
\hline rs2456777 & N/A & 0.39 & N/A & N/A & N/A & 0.46 & $\mathrm{~N} / \mathrm{A}$ & $\mathrm{N} / \mathrm{A}$ \\
\hline rs2456778 & & & & & & & & \\
\hline
\end{tabular}

p values in the generalized linear model are shown. The rs2456777/rs2456778 haplotype has more than two alleles and was applied to the Geno_group model only. Bold indicates $\mathrm{p}<0.05$.

\section{Discussion}

CDC2 is thought to be one of the main candidate kinases involved in paired helical filament-tau formation [23]. Previously, it has been shown that the occurrence of hyperphosphorylated tau correlates with cell division, differentiation and mitosis. The selective accumulation of CDC2 in neurons bearing neurofibrillary tangles indicates that a mitotic posttranslational mechanism might contribute to the paired helical filament-tau formation in $\mathrm{AD}$ [24]. Johansson et al. [25] reported that an insertion/ deletion polymorphism influences total tau protein levels in the cerebrospinal fluid using analysis of continuous traits.

We have conducted a comprehensive analysis of the association between six CDC2 gene polymorphisms spanning the entire length of the gene and the disease risk in both case-control and family-based samples. Johans- son et al. [25] sequenced all coding exons, flanking intronic sequences and the promoter region in $10 \mathrm{AD}$ cases and 10 controls and found three polymorphisms [EX6 + 7I/D (rs3212319), rs2456777 and rs2456778], all within $74 \mathrm{bp}$ of each other. We genotyped these three SNPs and three additional SNPs to cover the region. These SNPs demonstrated substantial LD with each other (D' varies from 0.39 to 0.73 ). Although the CDC2 locus is an obvious functional and positional candidate locus for $\mathrm{AD}$, the detailed genetic study presented here did not find evidence for an association with AD. Our study has the advantage of having both a large set of unrelated cases and controls and a large, well-characterized family sample. To explore our statistical power to detect allele frequency differences between cases and controls, we estimated power in our samples. Given the OR of 1.78 (95\% CI 1.182.68 ) and the probability of exposure of 0.35 in controls [13], we have $99 \%$ power to detect the disease-associated 
variation. Given our sample size, we still have $80 \%$ power to detect the variation even when the OR equals 1.38.

Although these six SNPs are in LD with each other, there are no obvious LD blocks. We cannot exclude the possibility that there are variants (rare or common) associated with $\mathrm{AD}$ in regulatory elements outside the $\mathrm{CDC} 2$ coding region and that they are not in strong LD with any of the SNPs that we have genotyped. The detection of such alleles, particularly when they are of low frequency, remains a challenge for molecular genetic studies. However, even if this is the case, it does not explain the discrepancy between our results and the earlier report. Although the gene showed the effect on $\mathrm{AAO}$ at $\mathrm{p}=$ 0.01 , the effect became non-significant after the confounders were considered.

In conclusion, we did not find the association with CDC2 polymorphisms in our large case-control and fam- ily samples, and this suggests that the variations in the CDC2 gene do not have a significant effect on the risk of LOAD. Although CDC2 may be pathophysiologically related to $\mathrm{AD}$, the contribution of common genetic variants of this gene to the risk for developing $\mathrm{AD}$ is likely to be low in Caucasian Americans.

\section{Acknowledgments}

We would like to thank all of the families who participated in this study. This study was supported by NIH grants AG019757, AG021547, AG20135, and a grant from the Alzheimer Association (IIRG-00-2006). Funding for collection and distribution of NCRAD samples was provided, in the past, by NIH grant AG21886. This work used the core resources of the General Clinical Research Center (MO1 RR-00095) and the CHGR at Vanderbilt University, and the $\mathrm{CHG}$ at Duke University.

\section{References}

1 Francis PT, Palmer AM, Snape M, Wilcock GK: The cholinergic hypothesis of Alzheimer's disease: a review of progress. J Neurol Neurosurg Psychiatry 1999;66:137-147.

2 Guttman R, Altman RD, Nielsen NH: Alzheimer disease. Report of the Council on Scientific Affairs. Arch Fam Med 1999;8:347353.

-3 Wisniewski T, Golabek A, Matsubara E, Ghiso J, Frangione B: Apolipoprotein E: binding to soluble Alzheimer beta-amyloid. Biochem Biophys Res Commun 1993;192:359-365.

$\checkmark 4$ Myers AJ, Goate AM: The genetics of lateonset Alzheimer's disease. Curr Opin Neurol 2001; 14:433-440.

5 Corder EH, Saunders AM, Strittmatter WJ, et al: Gene dose of apolipoprotein E type 4 allele and the risk of Alzheimer's disease in late onset families. Science 1993;261:921923.

-6 Pericak-Vance MA, Grubber J, Bailey LR, et al: Identification of novel genes in late-onset Alzheimer's disease. Exp Gerontol 2000;35: 1343-1352.

7 Myers A, Wavrant De-Vrieze F, Holmans P, et al: Full genome screen for Alzheimer disease: stage II analysis. Am J Med Genet 2002; 114:235-244.

-8 Mayeux R, Lee JH, Romas SN, et al: Chromosome-12 mapping of late-onset Alzheimer disease among Caribbean Hispanics. Am J Hum Genet 2002;70:237-243.

9 Liang X, Schnetz-Boutaud N, Kenealy SJ, et al: Covariate analysis of late-onset Alzheimer disease refines the chromosome 12 locus. Mol Psychiatry 2006;11:280-285.
0 Bertram L, Blacker D, Mullin K, et al: Evidence for genetic linkage of Alzheimer's disease to chromosome 10q. Science 2000;290: 2302-2303.

11 Myers A, Holmans P, Marshall H, et al: Susceptibility locus for Alzheimer's disease on chromosome 10. Science 2000;290:23042305.

12 Ertekin-Taner N, Graff-Radford N, Younkin $\mathrm{LH}$, et al: Linkage of plasma $\mathrm{A} \beta 42$ to a quantitative locus on chromosome 10 in late-onset Alzheimer's disease pedigrees. Science 2000;290:2303-2304.

13 Johansson A, Hampel H, Faltraco F, et al: Increased frequency of a new polymorphism in the cell division cycle $2(\mathrm{cdc} 2)$ gene in patients with Alzheimer's disease and frontotemporal dementia. Neurosci Lett 2003;340: 69-73.

14 McKhann G, Drachman G, Folstein M: Clinical diagnosis of Alzheimer's disease: report of the NINCDS-ADRDA Work Group under the auspices of the Department of Health and Human Services Task Force on Alzheimer's disease. Neurology 1984;34:939-944.

15 Rimmler J, McDowell J, Slotterbeck BD, et al: Development of a data coordinating center (DCC): data quality control for complex disease studies. Am J Hum Genet 1998;63: A240.

16 Zaykin D, Zhivotovsky L, Weir BS: Exact tests for association between alleles at arbitrary numbers of loci. Genetica 1995;96:169178. -17 Abecasis GR, Cookson WO: GOLD - graph-
ical overview of linkage disequilibrium. Bioinformatics 2000;16:182-183.
18 Martin ER, Monks SA, Warren LL, Kaplan NL: A test for linkage and association in general pedigrees: the pedigree disequilibrium test. Am J Hum Genet 2000;67:146-154.

19 Martin ER, Bass MP, Gilbert JR, PericakVance MA, Hauser ER: Genotype-based association test for general pedigrees: the genotype-PDT. Genet Epidemiol 2003;25:203213.

20 Ott J: Analysis of Human Genetic Linkage. Baltimore, Johns Hopkins University Press, 1999.

-21 Hauser ER, Watanabe RM, Duren WL, Bass MP, Langefeld CD, Boehnke M: Ordered subset analysis in genetic linkage mapping of complex traits. Genet Epidemiol 2004;27: 53-63.

22 Dupont WD, Plummer WD Jr: Power and sample size calculations. A review and computer program. Control Clin Trials 1990;11: $116-128$.

23 Baumann K, Mandelkow EM, Biernat J, et al: Abnormal Alzheimer-like phosphorylation of tau-protein by cyclin-dependent kinases cdk2 and cdk5. FEBS Lett 1993;336:417424.

24 Vincent I, Jicha G, Rosado M, Dickson DW: Aberrant expression of mitotic cdc2/cyclin B1 kinase in degenerating neurons of Alzheimer's disease brain. J Neurosci 1997;17: 3588-3598.

25 Johansson A, Zetterberg H, Hampel H, et al: Genetic association of CDC2 with cerebrospinal fluid tau in Alzheimer's disease. Dement Geriatr Cogn Disord 2005;20:367374. 